\title{
The streamers dynamics study by an intelligent system based on Neural Networks
}

\author{
Fouad Khodja \\ Department of engineering \\ University Djillali Liabes \\ Sidi Belabes, Algeria \\ khodjafouad@gmail.com
}

\author{
Younes Mimoun, Riad Lakhdar Kherfane \\ Department of engineering \\ University Djillali Liabes \\ Sidi Belabes, Algeria \\ younesmi@yahoo.fr/rilakh@yahoo.fr
}

Received: January 10, 2021. Revised: February 24, 2021. Accepted: March 12, 2021. Published: March 19, 2021.

\begin{abstract}
The formation and propagation of streamers is an important precursor to determine the characteristics of electrical breakdown of many $\mathrm{HV}$ electrode configurations. Understanding of the study of the interaction between the polymer surface and the development process of the streamer is of major importance when we want to improve internal and external performance insulation systems. In this context, a numerical tool using neural networks is developed. This model allows evaluating the speed of streamers as a function of the amplitude of voltage initiation and the nature of the insulating materials. For this, a database was created to train the neural model from a laboratory model. This investigation builds a database for predicting the propagation of streamers on the polymers surface by different neuronal methods and this presents an interesting tool for estimating the propagation phenomena in functions of very important parameters.
\end{abstract}

Keywords-Organic Insulators; Pre disruptive phenomena; Streamers; Artificial Neural Networks; Learning process; Neural Networks Feedforward; Radial basis Function.

\section{INTRODUCTION}

Formation of a streamer is due to photo ionization mechanisms occurring within the primary avalanche. The electrons accelerated by the electric field excited by collisions of neutral molecules which return to their ground state with emission of a photon. The head of the avalanche is home of a significant release of photons that are absorbed by the surrounding gas.

If the electron produced is located in the vicinity of the primary avalanche, it will create a new so-called secondary avalanche, with the same mechanism of electron multiplication, but the avalanche is now growing in a field that is enhanced by the presence of the positive space charge. Indeed, in an electric field sufficient to create the boot, the electron velocity is about 100 times higher than that of positive ions, so that the avalanche develops as a cloud of electrons leaving behind positive ions near stationary, then the avalanche leads to the formation of a dipole structure as shown in fig.1:

-a region (towards the anode) of high electron density, ions.

-a region (towards the cathode) of a high density of positive
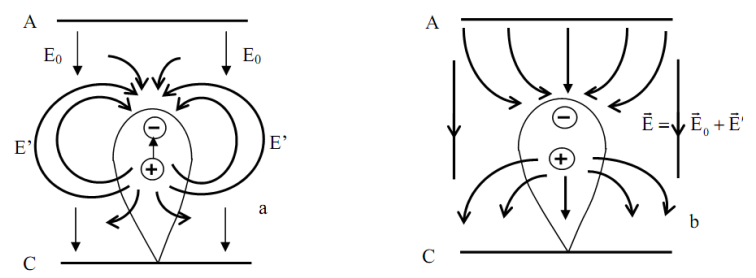

Fig. 1. Electron Avalanche

Therefore the separation of electrons and ions generates a significant space charge produces an electric field $\left(\overrightarrow{E^{x}}\right)$ of dipolar structure and opposing the separation, which is vectorially added to the external field (Fig.1).

\section{MEASUREMENT TECHNIQUES}

\section{A. Optical Measurement}

The luminous phenomena occurring within the range can be recorded by cameras, streak cameras called ultra fast image converters, photomultipliers, spectroscopy and strioscopy. Cameras whose optical axes are placed at $90^{\circ}$ from one another possible to reconstruct the actual length of the discharge in all three dimensions.

The image converter restores both the axial development of the discharge and its temporal development.

Photomultipliers can be used to measure streamers in relatively small intervals [4] over large intervals in Fig. 2.

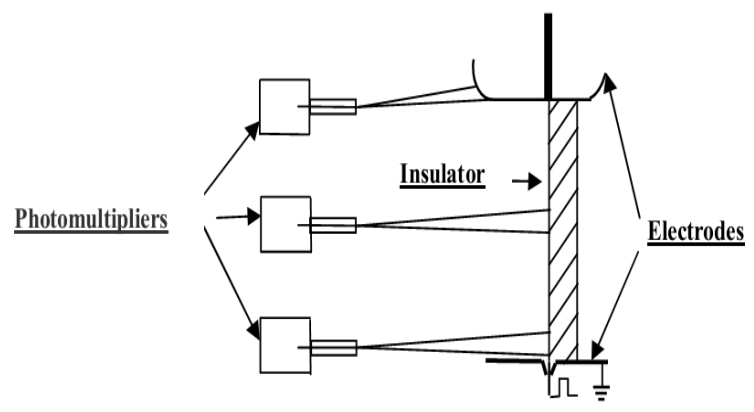

Fig. 2. Schematic diagram of the arrangement of electrodes with photomultipliers 


\section{B. Insulated Materials Used}

Intervals involved in Fig. 2 are polymers. In the electrical field, the scope of application of insulating organic solids (polymers) is expanded: power transmission lines, telecommunication cables, capacitors, alternators, electric motors, electronic systems and terrestrial power components and on board satellites...

The use of these materials in electrical insulation has several advantages such as, excellent electrical properties (resistivity, stiffness, and permittivity), good mechanical strength and easy implementation, low weight and for some possibility of recycling [5]. These materials had excellent electrical insulating properties because of its low relative permittivity, low dissipation factor, good stability over a wide frequency range, and high dielectric breakdown strength [6].

The polymeric materials have a complex structure which leads to different properties within the same material. Knowledge of the structure of an individual macromolecule, but also the arrangement of the macromolecules relative to each other, is essential to understand the complexity of these systems. The microstructure of a polymer insulator dictates the physical, mechanical and electrical properties that are expected of this material [5].

Insulating materials used in the experimental [4] are:

1 Polytetrafluoroethylene (PTFE).

2 PTFE carbonized (CPTFE).

3 Molybdenumdisuflide PTFE (MPTFE).

4 Nylon.

5 Ceramic coating (CERG).

\section{NEURAL NETWORKS}

\section{A. Learning Process}

Among the desirable properties for a neural network, probably the most fundamental is the ability to learn from its environment, to improve its performance through a learning process [7].

Learning is a dynamic and iterative process for changing the parameters of a network in response to the stimuli it receives from its environment. The type of learning is determined by how parameter changes occur. Thus, the network may improve overtime [7].

That to say the weight $w_{i, j}$ connecting the neuron $i$ to its input $j$.At time $t$, a change $\Delta w_{i, j}$ of weight can be simply expressed as follows:

$$
\Delta w_{i, j}(t)=w_{i, j}(t+1)-w_{i, j}(t)
$$

and, therefore,

$$
w_{i, j}(t+1)=w_{i, j}(t)+\Delta w_{i, j}(t)
$$

With $w_{i, j}(t+1)$ and $w_{i, j}(t)$ representing respectively the values of the new and old weight $w_{i, j}$.

A set of clear rules for carrying out such a process of adaptation of the weights is called learning algorithm of the network [7].

\section{B. Multilayer Perceptron}

These are best known neural networks. A perceptron is an artificial neural network feedforward type ,i.e., direct propagation.

There is a three-layer perceptron. The first is the input (it is not considered neural layer by some authors because it is linear and only distributes the input variables). The second is called hidden layer (or intermediate layer) and is the heart of the neural network. Its activation functions are sigmoid type. The third, consisting here of a single neuron is the output layer. Its activation function is the linear bounded [8].

Its learning is supervised type, by correcting errors. In this case only, the error signal is "feeds back" to the inputs to update the weights of neurons [7]. This is the error backpopagation method.

The multilayer perceptron is a neural network used for most problems of approximation, classification and prediction. It usually consists of two or three layers of neurons fully connected [7].

One problem of using neural networks is in the choice of topology. For example there is no general rule that gives the number of neurons to remember for the intermediate layer. This choice is application-specific and, in general, these are just arbitrary choices of which we verify later the validity [8].

\section{Radial Basis Function Networks}

Neural networks Feedforward (NNF) and neural networks based on radial basis function (RBFN) are a class of models widely used in nonlinear system identification [9], [10]. Justification for this is that these networks with one hidden layer can approximate any continuous function having a finite number of discontinuities [11], [12].

A net boost for RBFN neural networks has been observed in recent years because they offer major advantages over commonly used to NNF. These benefits include the complexity of the model and not a lighter load during learning [13].

Neural networks RBFN (Radial Basis Function Network) have been developed by Moody and Darken [14]. They have proven successful in several areas since they can approach several types of functions [15].

The network is a network feedforward RBFN composed of three layers: an input layer, a hidden layer and output layer. The activation function in the hidden layer is a radial function. The activation function most commonly used is the Gaussian function [16].

The input layer is used as a distributor of inputs to the hidden layer. Unlike NNF, the values of entries in the input 
layer are routed directly to the hidden layer without being multiplied by the weight values.

The unit of the hidden layer measures the distance between the input vector and the center of the radial function, and produces an output value depending on the distance. The center of the radial function is called the reference vector [17].

\section{PROBLEM FORMULATION}

The algorithms of artificial neural networks (ANN) have been applied successfully in many applications in many fields. In the field of high voltage, the ANN has also been applied effectively to the first partial discharges [18].

The major field of application of ANN is the estimation of functions, because the useful properties such as adaptability and nonlinearity are in agreement with the estimation of the equation describing functions when the function is unknown and the only requirement is to have a representative sample of the behaviour of the function. In this work, learning the important data have been made of experimental studies on the propagation of streamers on the surface of insulators [4].More detailed studies and tests were conducted to determine the parameters of the ANN to give better results and to have a quality model. A certain approach using ANN as an estimator function was used to effectively model the propagation velocity of streamers $V$ depending on several parameters:

The nature of the polymer, represented by $T$.

The initiation voltage $u$.

The relationship is as follows:

$$
V=f(D, T)
$$

It was found that when learning is complete, the ANN is able to estimate the speeds of different functions efficiently and effectively. This study attempts to show the effectiveness of ANN as function estimator in studies of the propagation of streamers [4]. Modelling the propagation velocities of the streamer as a function of the applied voltage $u$ and the type of material $T$ by neural networks as a function estimated with the aid of experimental data.

Each learning model includes two input parameters $u$ and $T$, and an output parameter which is the corresponding values of $V$

The neural network model has two input nodes and one output node [4].

Once the neural network trained by the training data, the network is tested by the test data.

The collection of experimental data was obtained from the experimental curve from article [4]. The shape of the curve of the measured velocities as a function of applied voltage is given as follows:

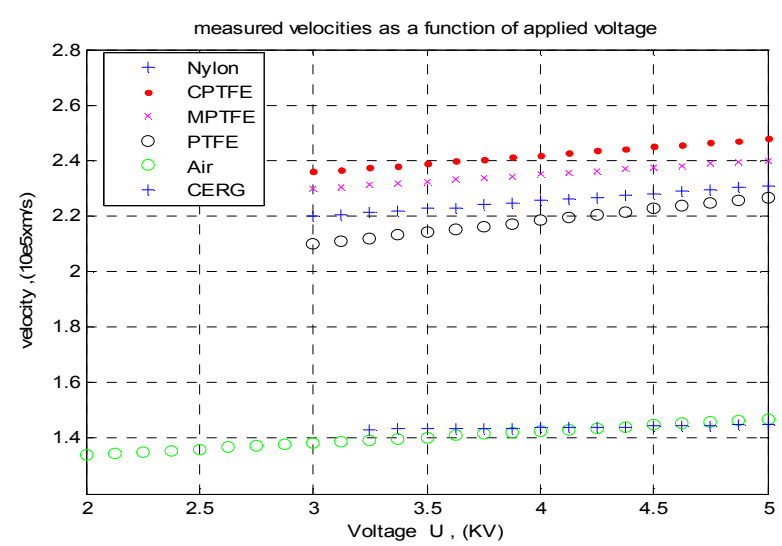

Fig. 3. Velocities measured by the voltages applied

\section{A. The Learning Algorithm}

The root mean square error learning RMSE is given by:

$$
R M S E=\frac{1}{N P \cdot N_{k}} \sum_{p=1}^{N P} \sum_{k=1}^{N k}\left(t_{p k}-O_{p k}\right)^{2}
$$

The accuracy of learning is measured by the RMSE whose expression was given by equation (4), and test accuracy is measured by the percentage of the mean absolute error (MAE $\%$, given by:

$$
\% M A E=\frac{\sum\left[\left|t_{K}-O_{k}\right| / t_{k}\right]}{n} \times 100
$$

Where:

$t_{k}$ is the experimental result corresponding to the given test input to the output neuron $k$,

$O_{k}$ is the output determined for the output neuron $k$ corresponding to the data test input, and $n$ is the number of input test data.

\section{RESUlTS AND DisCUSSION}

\section{A. Choice of the Arrangement and the Number of Neurons}

We begin by a single neuron in the first layer, all calculations are performed for the second arrangement, and the number of neurons in the 1st, 2nd and 3rd layer is applied to other arrangements. We do the same thing with two neurons in the first layer, then three and four neurons the following summary table is obtained. 
TABLE I. CHOICE OF THE ARRANGEMENT AND THE NUMBER OF NEURONS FOR LOGSIG FUNCTION

\begin{tabular}{|c|c|c|c|}
\hline & \multicolumn{3}{|c|}{$\begin{array}{c}\text { Logsig Function, Arrangement } 8, \\
\text { Number of layers : } 3\end{array}$} \\
\hline & $\begin{array}{c}\begin{array}{c}\text { Number of } \\
\text { epochs }\end{array} \\
\end{array}$ & RMSE & $M A E$ \\
\hline $\begin{array}{l}\text { 1st layer: } 1 \text { neuron } \\
\text { 2nd layer: } 1 \text { neuron } \\
\text { 3rd layer: } 7 \text { neurons }\end{array}$ & 2000 & $2.8577 \mathrm{e}-004$ & 0.0213 \\
\hline $\begin{array}{l}\text { 3rd layer: } 7 \text { neurons } \\
\text { 1st layer: } 2 \text { neurons }\end{array}$ & & & \\
\hline $\begin{array}{l}\text { 2nd layer: } 2 \text { neurons } \\
\text { 3rd layer:11 neurons }\end{array}$ & 1000 & $3.1362 \mathrm{e}-004$ & 0.0204 \\
\hline $\begin{array}{l}\text { 1st layer: } 3 \text { neurons } \\
\text { 2nd layer: } 9 \text { neurons } \\
\text { 3rd laver:12 neurons }\end{array}$ & 1000 & $2.5530 \mathrm{e}-004$ & 0.0208 \\
\hline $\begin{array}{l}\text { 1st layer: } 4 \text { neurons } \\
\text { 2nd layer: } 3 \text { neurons } \\
\text { 3rd layer: } 9 \text { neurons }\end{array}$ & 2000 & $2.9046 \mathrm{e}-004$ & 0.0208 \\
\hline
\end{tabular}

The best result was obtained for 02 neurons in the first hidden layer, 02 neurons in the second hidden layer and 11 neurons in the third hidden layer. The number of iterations is now 1000 iterations.

We change the number of iterations from 500 iterations to 10000 iterations.

TABLE II. EFFECT OF THE NUMBER OF ITERATIONS FOR LOGSIG FUNCTION

\begin{tabular}{|l|l|l|}
\hline \multicolumn{3}{|c|}{ Logsig Function, Arrangement 8, Number of layers : 3} \\
\hline $\boldsymbol{1}^{\text {st }}$ layer: 2 neurons & $\boldsymbol{2}^{\text {nd }}$ layer: 2 neurons & $\mathbf{3}^{\text {rd }}$ layer:11neurons \\
\hline Number of epochs & RMSE & MAE \\
\hline 500 & $3.6131 \mathrm{e}-004$ & 0.0211 \\
\hline 1000 & $3.1362 \mathrm{e}-004$ & 0.0204 \\
\hline 2000 & $3.0301 \mathrm{e}-004$ & 0.0205 \\
\hline 3000 & $2.9838 \mathrm{e}-004$ & 0.0206 \\
\hline 4000 & $2.9530 \mathrm{e}-004$ & 0.0208 \\
\hline 5000 & $2.9324 \mathrm{e}-004$ & 0.0210 \\
\hline 10000 & $2.4590 \mathrm{e}-004$ & 0.0217 \\
\hline
\end{tabular}

The best result is obtained for 1000 iterations, for the case of 02 neurons in the first hidden layer.

The learning of the neural network is represented by the following Figure:

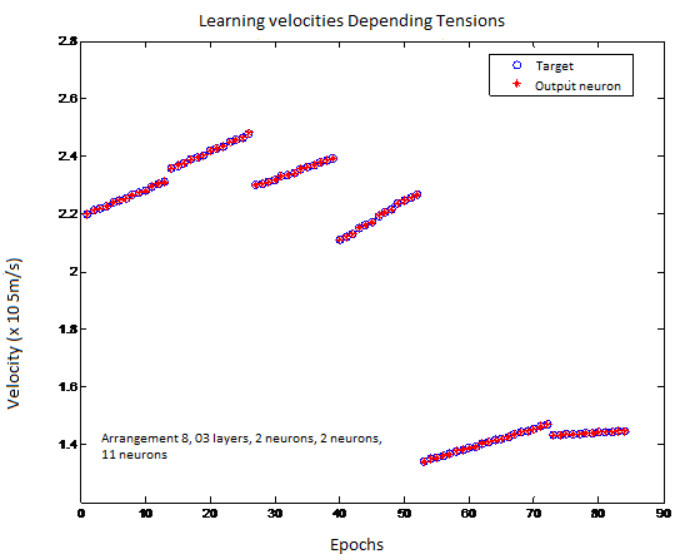

Fig. 4. Learning of the neural network
Testing the neural network is that of Fig. 5 .

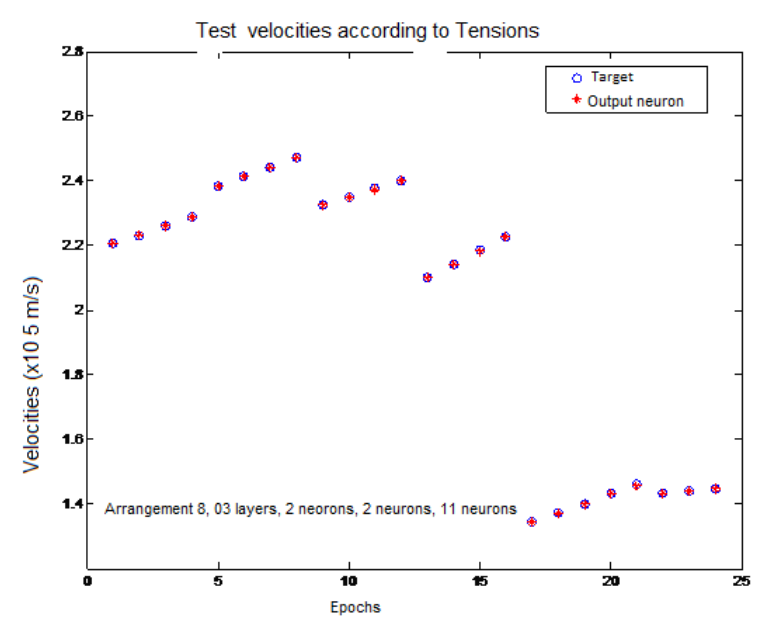

Fig. 5. Test of the neural network

B. Effect of changing activation function on RMSE and MAE

TABLE III. CHOICE OF THE ARRANGEMENT AND THE NUMBER OF NEURONS FOR TANSIG FUNCTION

\begin{tabular}{|c|c|c|c|}
\hline & \multicolumn{3}{|c|}{$\begin{array}{c}\text { Tansig Function, Arrangement 6, } \\
\text { Number of layers : } 3\end{array}$} \\
\hline & $\begin{array}{c}\text { Number of } \\
\text { epochs }\end{array}$ & RMSE & $\boldsymbol{M A E}$ \\
\hline $1^{\text {st }}$ layer: 1 neuron & \multirow[b]{2}{*}{2000} & \multirow[b]{2}{*}{0.0103} & \multirow[b]{2}{*}{0.2717} \\
\hline $\begin{array}{l}2^{\text {nd }} \text { layer: } 1 \text { neuron } \\
3^{\text {rd }} \text { layer: } 7 \text { neurons }\end{array}$ & & & \\
\hline $1^{\text {st }}$ layer: 2 neurons & \multirow[b]{2}{*}{1000} & \multirow[b]{2}{*}{0.0505} & \multirow[b]{2}{*}{1.5603} \\
\hline $\begin{array}{l}2^{\text {nd }} \text { layer: } 2 \text { neurons } \\
3^{\text {rd }} \text { layer: } 11 \text { neurons }\end{array}$ & & & \\
\hline $1^{\text {st }}$ layer: 3 neurons & \multirow[b]{2}{*}{1000} & \multirow[b]{2}{*}{$1.8818 \mathrm{e}-004$} & \multirow[b]{2}{*}{0.0343} \\
\hline $\begin{array}{l}2^{\text {nd }} \text { layer: } 9 \text { neurons } \\
3^{\text {rd }} \text { layer: } 12 \text { neurons } \\
\end{array}$ & & & \\
\hline $1^{\text {st }}$ layer: 4 neurons & \multirow[b]{2}{*}{2000} & \multirow[b]{2}{*}{0.0030} & \multirow[b]{2}{*}{0.1053} \\
\hline $\begin{array}{l}2^{\text {nd }} \text { layer: } 3 \text { neurons } \\
3^{\text {rd }} \text { layer: } 9 \text { neurons }\end{array}$ & & & \\
\hline
\end{tabular}

The best learning error for tansig function for 1000 iterations, while for the test error MAE, the lowest being for logsig function for 1000 iterations too.

TABLE IV. EFFECT OF THE NUMBER OF ITERATIONS FOR TANSIG FUNCTION

\begin{tabular}{|l|l|l|}
\hline \multicolumn{2}{|c|}{ Tansig Function, Arrangement 6, Number of layers : 3} \\
\hline $\boldsymbol{1}^{\text {st }}$ layer: 3 neurons & $2^{\text {nd }}$ layer: 9 neurons & $\mathbf{3}^{\text {rd }}$ layer: 12 neurons \\
\hline Number of epochs & RMSE & MAE \\
\hline 500 & $2.0609 \mathrm{e}-004$ & 0.0259 \\
\hline 1000 & $1.8818 \mathrm{e}-004$ & 0.0343 \\
\hline 2000 & $1.4680 \mathrm{e}-004$ & 0.0477 \\
\hline 3000 & $1.4124 \mathrm{e}-004$ & 0.0526 \\
\hline 4000 & $1.3299 \mathrm{e}-004$ & 0.1147 \\
\hline 5000 & $1.0685 \mathrm{e}-004$ & 0.3703 \\
\hline 10000 & $1.2829 \mathrm{e}-005$ & 0.5559 \\
\hline
\end{tabular}

The increase in the number of iterations in this case has the effect of reducing the learning error for tansig function for 
10,000 iterations. The error on the test remains the lowest for logsig function for only 1000 iterations.

\section{Comparison between Feedforward and Radial Basis Function Networks}

TABLE V. SUMMARY TABLE BETWEEN FEEDFORWARD AND RBF NETWORKS

\begin{tabular}{|l|c|c|c|}
\hline & \multicolumn{2}{|c|}{$\begin{array}{c}\text { Feedforward Network } \\
\text { (Trainlm function) }\end{array}$} & $\begin{array}{c}\text { Radial Basis } \\
\text { Function Networks } \\
\text { (Newrb) }\end{array}$ \\
\hline & Logsig & Tansig & \multirow{2}{*}{ RMSE } \\
\hline & $\boldsymbol{R M S E}$ & $\boldsymbol{M A E}$ & \\
\hline 01 layer & $2.3910 \mathrm{e}-004$ & $2.2327 \mathrm{e}-004$ & \multirow{2}{*}{$2.9883 \mathrm{E}-004$} \\
\hline 02 layers & $2.3292 \mathrm{e}-004$ & $2.1608 \mathrm{e}-004$ & \\
\hline 03 layers & $2.4590 \mathrm{e}-004$ & $1.2829 \mathrm{e}-005$ & \\
\hline
\end{tabular}

The best RMSE was obtained for the Feedforward network for the learning function Trainlm and the activation function tansig.

The comparative curves of the experimental velocities (measured) and simulated according to voltages applied to the streamer, for different insulations and for air, are given in Figure the 8 following:

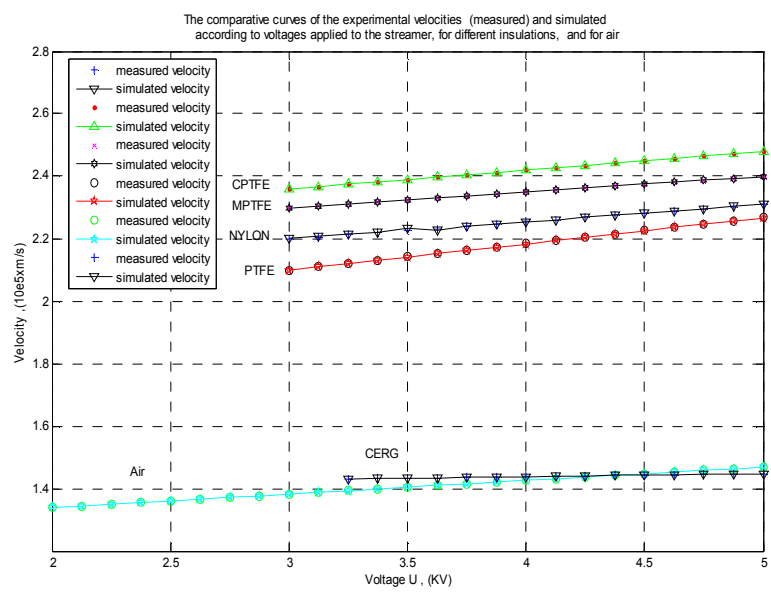

Fig. 6. Comparative curves of measured and simulated speeds depending on applied voltages

\section{CONCLUSIONS}

The best result concerning the error of learning or RMSE is given for 03 hidden layers.

The number of iterations that gave the best result is 10000 .

The best arrangement is the arrangement No. 06 .

The activation function used in hidden layers is the function tansigmoïde.

The function used in learning is trainlm.
Concerning the learning error for the RBF network, the number of iterations is small (100 iterations) which increases the speed of learning.

\section{REFERENCES}

[1] G. Le Roy, C. Gary, B. Hutzler, J. Lalot, Ch. Dubanton , " Les propriétés diélectriques de l'air et les très hautes tensions ", Edition Eyrolles, Paris 1984.

[2] Recherches sur l'amorçage des grands intervalles d'air aux Renardières, Electra, n³5, juillet 1974.

[3] T. SUZUKI, " Breakdown process in rod-to-plane gaps with negative switching impulses', IEEE trans. On power Apparatus and systems, Vol.PAS 94 n².Juillet/aout 1977

[4] N.L. Allen and P.N.Mikropoulos, "Streamer propagation along insulating surfaces, IEEE Transaction on Dielectrics and Electrical Insulating, vol. 6 No. 3, June 1999.

[5] Nadine Lahoude, " Modélisation du vieillissement des isolants organiques sous contrainte électrique. Application à la fiabilité des matériaux", Thèse de Doctorat, 25 Mars 2009. Université de TOULOUSE.

[6] L. Li, N. Bowler, M. R. Kessler and S. H. Yoon, ' Dielectric Response of PTFE and ETFE Wiring Insulation to Thermal Exposure', IEEE Transactions on Dielectrics and Electrical Insulation, Vol. 17, No. 4; August 2010.

[7] Marc Parizeau, " Réseaux de neurones, GIF-21140 et GIF- 64326", UNIVERSITE DE LAVAL, automne 2004.

[8] Lotfi Baghli, 'Contribution à la commande de la machine asynchrone, utilisation de la logique floue, des réseaux de neurones et des algorithmes génétiques', janvier 1999, Université Henri Poincaré Nancy-I.

[9] K.S. Narenda, and K. Parthasarathy, "Identification and control of dynamical systems using neural networks", IEEE Transactions on Neural Networks, Vol.1, pp. 4-27, 1990.

[10] S. Chen, and S. A. Billings.' Neural networks for non-linear system modeling and identification", International Journal of Control, Vol.2, pp. 319-346, 1992

[11] K. Hornick, M. Stinchcombe and H. White, "Multilayer feedforward networks are universal approximators', Neural Networks, vol.2, pp. 359-366, 1989.

[12] J. Parks and I. W. Sandberg, "Universal approximation using radialbasis function networks", Neural Computation, Vol.3, pp 246-257, 1991.

[13] S. Lee, and R. M. Kil, “A Gaussian potential function network with hierarchically self-organizing learning', Neural Networks, Vol. 4, pp. 207-224, 1991.

[14] S. Haykin, 'Neural Networks : A Comprehensive Foundation', IEEE PRESS, 1994.

[15] J. Park, I.W. Sandberg, “Approximation and radial basis function network', Neural Computation, 5, 1993, pp. 305-316.

[16] A. Idri, S. Mbarki, A. Abran, "L'interprétation d'un réseau de neurones en estimation du coût de logiciels", Actes du 6ème Colloque Africain sur la recherche en Informatique (CARI'02), 14-17 octobre 2002, pp. 221-228.

[17] I. Yilmaz, N. Y. Erik, and O. Kaynar, 'Different types of learning algorithms of artificial neural network (ANN) models for prediction of gross calorific value (GCV) of coals', Scientific Research and Essays, Vol. 5(16), pp. 2242-2249, 18 August, 2010.

[18] A.S.Farag, " Estimation of Polluted Insulators Flashover Time Using Artificial Neural Networks“', IEEE, 1997.

\section{Creative Commons Attribution License 4.0 (Attribution 4.0 International, CC BY 4.0)}

This article is published under the terms of the Creative Commons Attribution License 4.0 https://creativecommons.org/licenses/by/4.0/deed.en US 